\title{
THE DYNAMIC FACTOR IN ENLARGEMENT OF CORONARY ARTERIAL ANASTOMOSES, AND PARADOXICAL CHANGES IN THE SUBENDOCARDIAL PLEXUS
}

\author{
BY \\ W. F. M. FULTON* \\ From the Department of Materia Medica and Therapeutics, University of Glasgow \\ Recejved March 21, 1963
}

Most investigators are agreed that frequent arterial anastomoses of relatively large size may be demonstrated in the coronary circulation in the presence of obliterative coronary artery disease. Evidence has been presented which shows that the enlarged anastomotic channels found in disease may in fact be derived from pre-existing, pre-capillary communications (Fulton, 1960, 1963a,b). Although there is a considerable body of information concerning the effects of coronary artery ligation on collateral blood flow in the experimental animal (Gregg, 1950) and on the increased incidence of readily injectable intercoronary communication in the presence of coronary occlusion (Zoll, Wessler, and Blumgart, 1951a), knowledge about the exact anastomotic pathways concerned and detail of their structural change is still somewhat sketchy.

Enlargement of anastomoses on the surface of the heart has tended to attract greater notice than have changes taking place in the deeper vessels. This is probably attributable to the relative ease with which the superficial vessels may be demonstrated. However, an arterial network in the inner zone of the left ventricle was described independently in the normal heart by Spalteholz $(1907,1924)$ and by Gross $(1921)$, and the subendocardial network has been shown to undergo great enlargement and to exert profound influence on the distribution of blood to the heart in coronary artery disease (Fulton, 1956, 1960, 1964b).

Apart from the observations made in the present investigation, enlargement of the vessels composing the subendocardial plexus of the left ventricle appears to have received little attention in pathology. It is perhaps for this reason that the apparent paradox of enlargement of these vessels under conditions of severe restriction of total blood flow to the heart has excited so little comment hitherto.

The manner in which the subendocardial arterial plexus of the left ventricle enlarges in the presence of coronary artery disease, and some factors that promote anastomotic enlargement at this site, and elsewhere in the heart, are considered in this communication.

\section{MATERIALS AND Methods}

A series of 59 hearts was investigated post mortem by a method that included stereo-arteriography. The series comprised 25 cases of coronary artery disease, 17 cases with heart disease other than coronary artery disease, 12 normal hearts, and 5 hearts that were normal save for increase in heart weight beyond normal limits. The material and technique of examination have been described in more detail elsewhere (Fulton, 1960, 1963a, c).

* Formerly Research Assistant in Cardiology in the University of Edinburgh. Present address: Johns Hopkins Hospital, Baltimore, Maryland, U.S.A. 


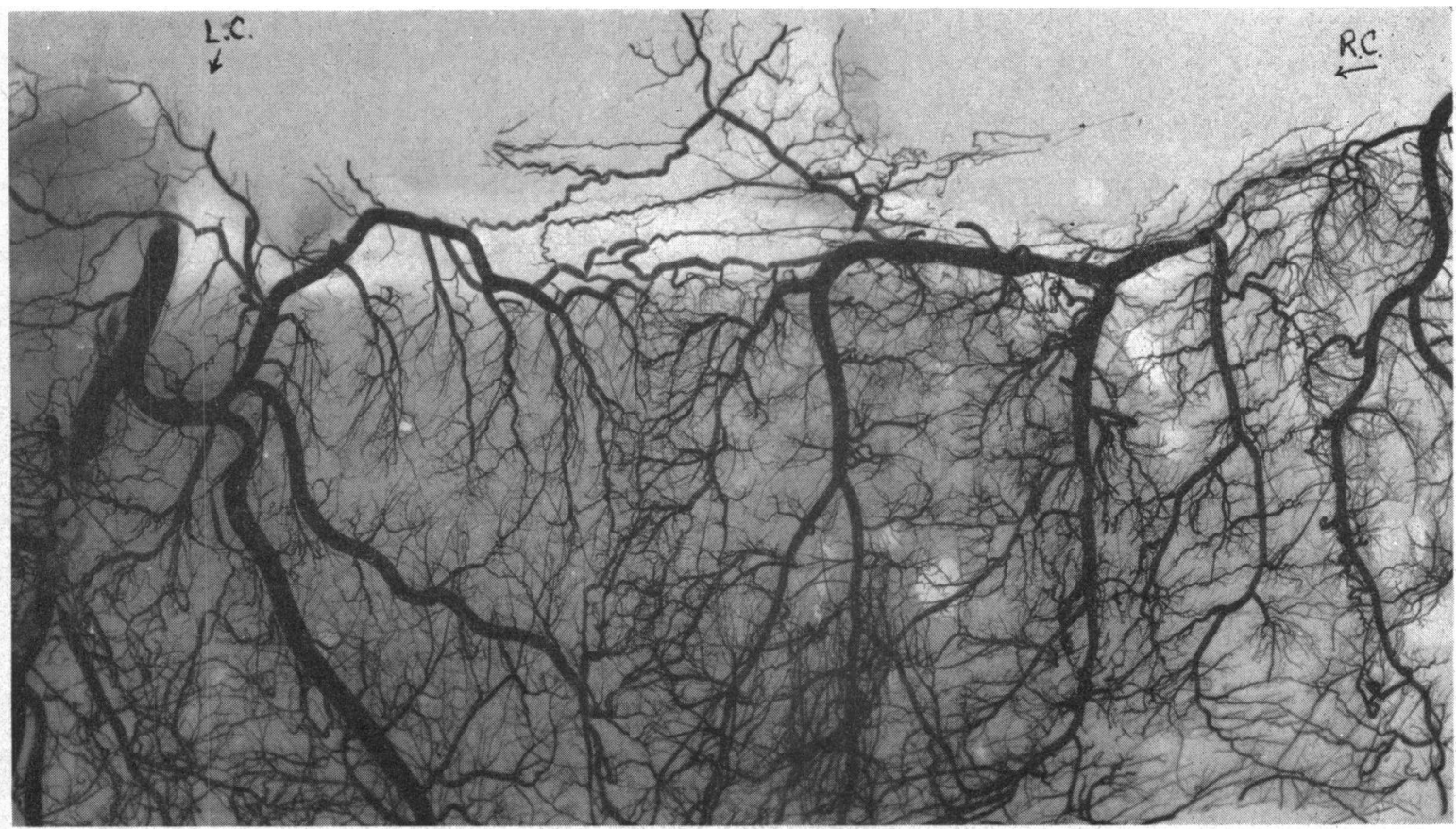

FIG. 1.-To the right of the illustration the right coronary artery shows occlusion by thrombosis of six months' duration. Before occlusion the artery was diseased but not obstructed. The pressure gradient created by occlusion has favoured flow from the left circumflex coronary artery through anastomoses and so provoked their enlargement. Enlarged anastomoses can be seen in the atrial circulation and can also be traced in the deeper layers of the left ventricle immediately below. The identification of the ventricular anastomoses is only reliably accomplished in stereo. Note that enlargement has taken place in vessels lying outside the area of ischæmia but carrying the augmented blood flow.

A radio-opaque injection medium (bismuth-oxychloride-gelatin) was introduced into both coronary arteries under controlled pressure, and differential pressure gradients were employed during the course of the injection. The standard maximum pressure used was $150 \mathrm{~mm}$. Hg. Stereoradiography was employed throughout, for the intact heart and for all portions yielded by partial dissection. The method of preliminary dissection of the heart was specially devised for the display of changes in the coronary vessels. The universal use of stereoscopy and transventricular sections contributed to the recognition of changes in the: deeper layers of the ventricles, which was a notable feature of this investigation.

TABLE I

INCIDENCE OF ENLARGEMENT OF BRANCHES OF UNOBSTRUCTED ARTERIES in Response to Augmented Collateral BloOD Flow, in 25 CaSes of Coronary ARTery Disease

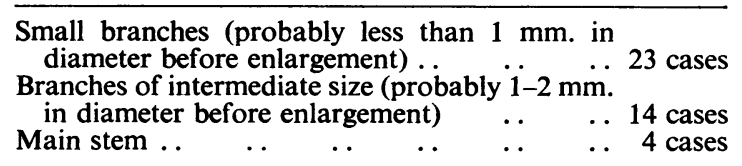

Note: 'Enlargement' records an impression, not a measurement. With experience in following the gradual' tapering of normal coronary arteries down to the finest twigs, it was possible to recognize lumen dimensions that exceeded the normal for that site. Similar vessels not involved in collateral blood flow were often available for com-. parison in the same heart. 
The Effect of Coronary Artery Occlusion on Arterial Anastomoses

1. Arteriographic Evidence in the Present Investigation. Description of anastomoses in the normal heart has already been given (Fulton, 1963a, b). No anastomotic developments in coronary artery disease were found to which there was no counterpart of smaller scale in the same region of a normal heart. Every gradation of change was observed from relatively slight departure from the normal anastomotic pattern to gross distortion of the coronary circulation with the formation of a network of wide intercommunicating channels. After careful reflection on the detailed arteriographic findings in the small vessels, in widely diverse individual cases, it was possible to recognize that essentially the same process was at work in all. Wherever obstruction to a coronary artery had introduced conditions favouring differential blood flow for a considerable time, adaptive enlargement of the small vessels of the heart was found. This was the common factor. The final arteriographic picture also reflected the original anatomy, the site, severity, and sequence of coronary artery occlusions and myocardial damage, and accordingly showed a great variety of configurations.

A typical example is illustrated in Fig. 1 in which the unobstructed branches of the left circumflex artery are on the left-hand side. On the right are the terminal branches of the right coronary artery which supplied the posterior wall of the left ventricle. This artery was occluded by thrombosis some six months before death (as judged from clinical features and related myocardial damage). Enlarged anastomotic channels may be seen linking the two arteries. Those in the left atrial wall and in the atrio-ventricular groove are well displayed. Stereoscopy is required to appreciate that in the depths of the left ventricular wall there are also numerous communications of similar calibre. (One of them can in fact be traced in this illustration-but only in three dimensions can one be certain that apparent continuity is not due to the overlapping of vessels.)

Careful consideration of the entire circulatory picture of this case, together with examination of the myocardium for ischæmic changes, permits the statement that ischæmia resulting from right coronary occlusion must have been greatest to the right of the midline in this illustration. Yet it is at the junctional zone and well into the territory of the unobstructed left coronary artery that the changes in the small vessels are most pronounced. This illustrates the important finding that enlargement of collateral vessels is not confined to the area of ischæmia but is found also in the branches that carry the relief blood supply from an artery that is fully patent. The significance of this point will be elaborated later (see Table I).

In order that a similar state of affairs may be appreciated in two dimensions, a transverse section through the ventricles is used, in Fig. 2. This shows enlargement of the subendocardial plexus in the posterior wall of the left ventricle, bordering an area of ischæmia, which arose in similar fashion to the last example from right coronary artery occlusion. Branches of the left circumflex coronary artery, which was unobstructed, lie on the right-hand side of the illustration. Nevertheless in this territory with good blood supply some dilatation of the subendocardial plexus can be discerned. Fig. 3 shows the arteriographic appearance of the transverse section of a healthy coronary circulation for comparison.

Even where only one coronary artery was occluded, it seemed that dilatation of the vessels of the subendocardial network increased in the course of time and became more diffuse as is shown in Fig. 4. Finally, as illustrated in Fig. 5, in the presence of widespread coronary artery obstruction of long standing, the vessels in the entire inner zone of the left ventricle may be converted into a network of wide intercommunicating channels (Fulton, 1956).

It was clear on anatomical grounds that augmentation of anastomotic blood flow was often accompanied by increase in diameter of collateral channels of the order of 5 or 10 , and sometimes 20 , times that found normally at equivalent sites (Fulton, 1964a). Increases of such orders call for stretching and growth of tissues and it is evident that a long time is required.

2. The Experimental Evidence. The experimental evidence on the effects of coronary artery occlusion on the collateral circulation of the heart has been reviewed by Gregg (1950) and by Blumgart et al.(1950). It is outside the scope of the present investigations and will be outlined very briefly. 


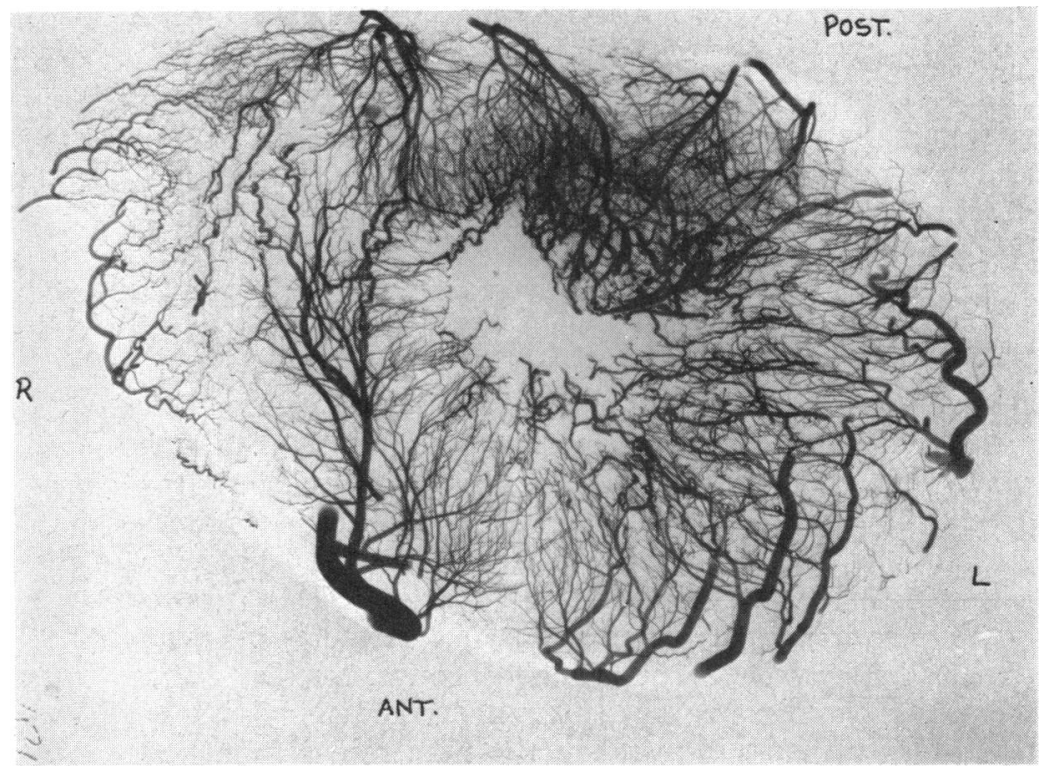

FIG. 2.-Enlargement of deep anastomoses as seen in transventricular section. Ischæmia was restricted to the posterior quadrant of the left ventricle and there is considerable increase in vascular density in this area. There is also enlargement of deep communicating vessels in neighbouring territories.

When the retrograde blood flow from the peripheral portion of a ligated coronary artery is measured, it is said to remain relatively constant for a few hours and thereafter to increase. A twofold increase takes place in 48 hours and a three- or fourfold increase in the course of one week (Gregg, 1950). Moreover, in the pig, an arteriographically demonstrable increase in the anastomotic pattern was provoked in the course of three weeks by partial ligation of a coronary artery

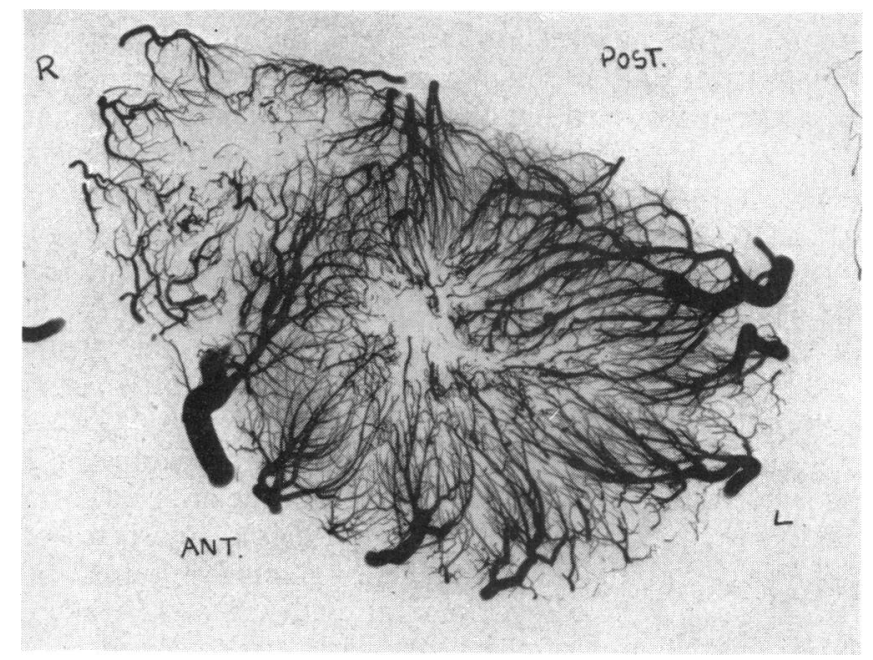

FIG. 3.-Transventricular section of the normal heart of a boy aged 14 years. 


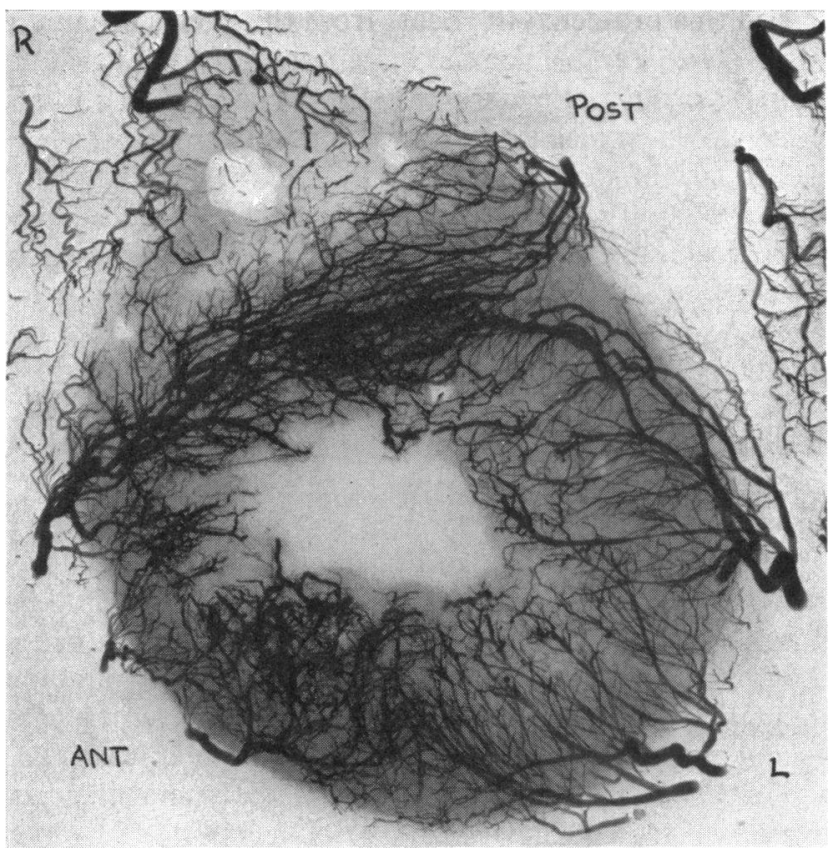

FIG. 4.-Transventricular section of a heart in which old-standing anterior descending artery occlusion had produced restricted myocardial damage in its territory. In time there was widespread enlargement of deep anastomoses of the left ventricle, but the greatest density is still found in the area of greatest ischæmia.

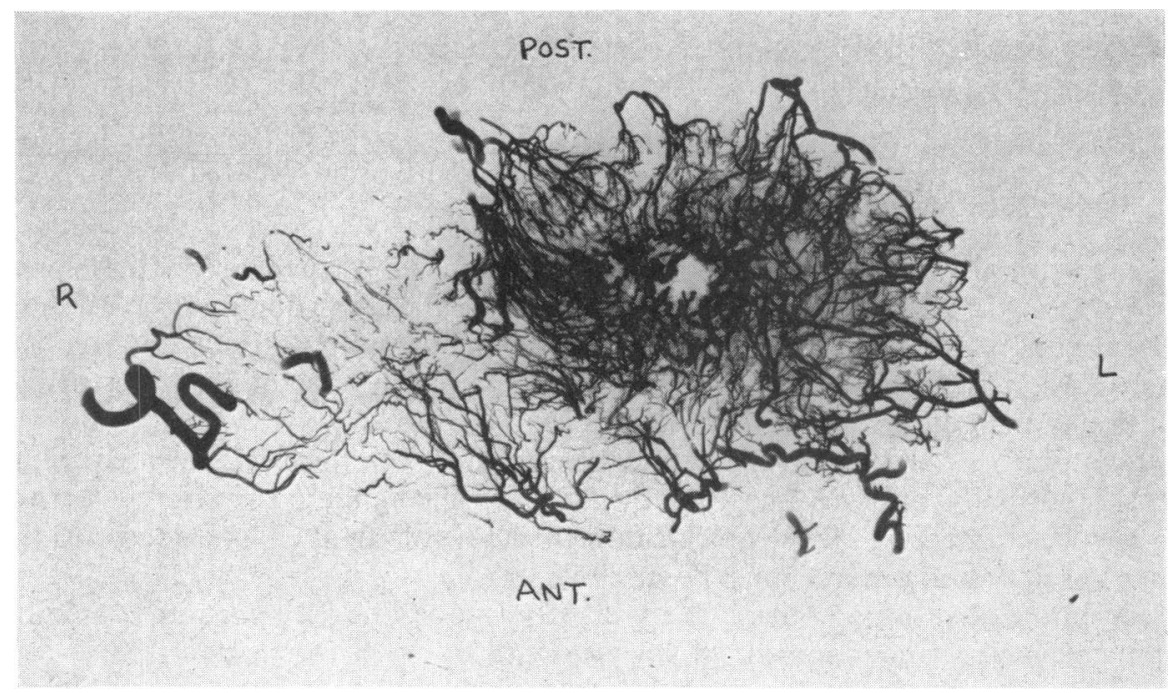

FIG. 5.-Transventricular section near the apex of a heart in which obliterative coronary artery disease was widespread and myocardial ischæmia was generalized. There is universal enlargement of the vessels composing the subendocardial plexus of the left ventricle. Fig. 4, Fulton (1956), is taken from the same heart at mid-ventricular level. Fig. 5 of Fulton (1963c) shows a similar situation. 
(Blumgart et al., 1950), and this protected the heart from the effects of complete occlusion. Sewell (1961) found that it was necessary to reduce the lumen area of the ligated coronary artery to 4-10 per cent of normal in order to produce strong stimulation of coronary collaterals.

It has been repeatedly shown in acute experiments that anoxia produced by a variety of means may augment the total coronary blood flow (Eckenhoff et al., 1947; Green and Wégria, 1942; Gregg and Green, 1940; Gregg, 1950). Presumably anoxia exerts an influence also on collateral blood flow, at any rate during the phase immediately following coronary artery occlusion.

On the other hand, there is little doubt that the slow augmentation of collateral blood flow observed over a week experimentally, and doubtless continuing for months or years in human pathology, involves mechanisms other than relaxation of muscular coats under the biochemical influence of anoxia.

3. Passive Versus Dynamic Factors in Anastomotic Enlargement. It is clear on experimental grounds that anoxia provokes increase in the total coronary blood flow. There is no reason to deny that anoxia may also exert a long-term influence on the enlargement of coronary anastomoses. In this connexion we note that enlargement of anastomoses has been observed in anæmia (Zoll, Wessler, and Schlesinger, 1951b; Eckstein, 1955). It is speculative, however, whether this is attributable directly to anoxia or indirectly to the increased cardiac action and coronary blood flow that accompanies anæmia. Likewise, anastomotic enlargement was found in the presence of cardiac hypertrophy due to valvular disease (Fulton, 1960) in which passive ischæmic and dynamic factors are both operative. In none of these conditions (aortic valvular disease excepted, in which special conditions of coronary blood flow obtain) was the degree of collateral enlargement comparable with that found in coronary artery disease.

Moreover, the influence of anoxia must surely be restricted to the area of ischæmia. Passive ischæmic factors cannot account for enlargement of vessels in neighbouring territories with good arterial blood supply. Thus it was evident that anoxia cannot be the only factor operative in the presence of coronary artery obstruction-nor indeed the most important. Altered conditions of blood flow consequent on coronary artery obstruction appeared to be the only common factor and the most powerful agency in the promotion of anastomotic enlargement.

\section{Dynamic Effects of Coronary Artery Occlusion on Arterial Anastomoses}

In 1669 Richard Lower (cited by Blumgart et al., 1950) wrote

". ... when the lumen of some artery has been too long obstructed or ligated, the blood busies itself in opening a wider channel for its passage in this vessel, must drive and buffet all the more into the next ones, until it has considerably dilated them to give itself room."

When a coronary artery is ligated experimentally, there is an immediate fall in the pressure distal to the obstruction. In time this pressure rises nearly to the level obtaining in the unobstructed artery. The rise in pressure, however, lags behind the augmentation of retrograde collateral blood flow (Gregg, 1950). There are no grounds for supposing that the hæmodynamic sequel to coronary artery occlusion in man differs in any material respect.

Distal to naturally occurring coronary artery occlusion, therefore, one may expect a fall in the resistance that normally opposes anastomotic flow from neighbouring arterial territories. The abnormal pressure gradient will favour blood flow through collateral channels towards the ischæmic area. Doubtless at first its volume must be small.

Where conditions favouring collateral flow had been operating for a considerable time, I have found varying degrees of enlargement of all vessels carrying the abnormal blood flow (Fulton, 1964a). This has also been noted by many workers, including Mautz and Beck (1937), in the experimental field, and by Wiggers (1950). Although many of the enlarged anastomotic vessels did in fact lie within the area of ischæmia, the point which I wish again to stress is that enlargement occurred characteristically also in the neighbouring non-ischæmic areas. Clearly only dynamic influences could be operative in these areas. 
Further, enlargement involved not only the communicating vessels themselves but also nearby stretches of the arterial branches feeding them (see Table I). In extreme cases it was evident that even the main stem itself had shared in the increase in lumen dimensions. Conversely, anastomoses and other small vessels were not noticeably enlarged in areas anatomically remote from the territory of an obstructed artery and where they did not contribute to the relief blood supply.

The probable course taken by the blood in life through abnormal routes could be reconstructed from examination of the stereo-arteriograms. Close examination of the changes that had taken place in the coronary circulation, in conjunction with the time relations of occlusions (so far as could be determined indirectly from clinical records and related myocardial damage), gave support to the concept that augmented blood flow, itself conditioned by abnormal pressure gradients, exerted a dynamic stimulus to the enlargement of anastomoses. Where only one major artery was obstructed and the others relatively unaffected, it was easy to visualize the direction of collateral blood flow and its influence in promoting enlargement of anastomotic channels. Anitschkow (1960) has stated that this is the setting in which the largest interarterial coronary anastomoses are observed and that collateral development is poorer where all three coronary arteries are severely stenosed. It will be apparent that my own findings do not entirely support this contention, but reveal a situation that is more complex, and at the same time less readily susceptible to explanation in terms of hæmodynamic stimulus to arterial enlargement.

For the most part in the present investigation superficial anastomoses contributed to the collateral supply only at the margins of the ischæmic area. (Distribution of blood might then follow the normal channels preserved distal to obstruction.) Deeply-placed anastomoses on the other hand were evidently responsible not only for bringing relief blood supply but also to a large extent for its distribution within the ischæmic area through abnormal pathways.

The part played by the subendocardial plexus was brought into prominence in this investigation. In extremes of dilatation of the deep vessels, as illustrated in Fig. 5 and described in detail (Fulton, 1956), there were some features that were not at first readily reconciled to the concept of dynamically determined anastomotic enlargement, as set out above.

In the cases referred to there was severe and widespread obliteration of the main coronary arteries and the total inflow of blood to the heart must have been greatly reduced. The persistence and severity of anginal symptoms during life was additional evidence of severely restricted total coronary blood flow. Nevertheless it was in these circumstances that enlargement of the deep anastomoses was found in the greatest degree. These vascular adjustments in its deeper layers had effected an even distribution of blood to the left ventricle but were powerless to augment its total volume. It seemed indeed that any useful level of compensatory change had been exceeded. Moreover an answer seemed to be demanded to the question, if blood flow was so severely restricted why then did the arterial structures not regress in size? The validity of the dynamic concept of coronary anastomotic enlargement was challenged. The problem will now be considered more closely.

\section{Interpretation of the Paradoxical Changes in the Subendocardial Plexus of THE LefT Ventricle}

It is a matter of common observation that the calibre of a developmentally normal artery and its branches bears some direct relation to the dimensions of the vascular bed supplied by it. Thus the diameter of an artery appears to reflect the volume of blood that it has been accustomed to carry during life. Examples may readily be seen in the course of arteriography of the heart, as in this investigation, or of other organs. Velocity of blood flow was regarded as the factor governing the development of collateral arteries by Longland (1953), who cites the observations of Nothnagel (1889), Hughes $(1935,1937)$, and Holman (1949) that bear directly on this point. Further, careful consideration of structural changes in the dimensions of blood vessels examined after death invites one to form tentative conclusions on the probable conditions of blood flow in them during life. At sites where measurement of blood flow is not feasible, such conclusions must remain speculative. 
Nevertheless a search for correlation between structure and function is more likely to travel in the direction of biological truth than is an argument founded on denial of their association. Again, in certain areas, as for instance in the deeper layers of the left ventricle, no evidence is available on this problem that is more direct in nature or more valid.

The intimate hæmodynamics of the deep vessels of the heart is not fully understood. Their situation has so far rendered them inaccessible to direct experimental observation in the beating heart. In these circumstances it seems justifiable to attempt to derive from their anatomical structure and situation, in conjunction with knowledge of other features of the heart's action, a concept of their probable function during the different phases of the cardiac cycle.

In the concept that will be developed, the evidence provided by the experiments on intramural pressures during cardiac contraction by Johnson and Di Palma (1939) and on arterial pulsation distal to occlusion by Wiggers (1950) has been correlated with the detailed picture of the deep myocardial vessels that has been provided by this investigation. The argument will be more readily followed if the vessels composing the subendocardial plexus are taken to be grossly dilated as in severe coronary artery disease (Fig. $3,4,5$ ), although what is to be said would apply equally to the deeper vessels in their normal condition, on a much smaller scale. It may be helpful to refer to the schematic drawing of the subendocardial plexus and its connexions with the epicardial arteries that appears in a previous communication (Fulton, 1963a, Fig. 4).

In order to explain more clearly what I believe may take place, I propose to regard the relatively wide-bore vessels of the subendocardial plexus, when taken together, as forming a sort of complex reservoir which is in direct communication with the epicardial vessels through a number of straight channels, as indicated in Fig. 6 . With each cardiac cycle, the pressure conditions that surround the deep vessels of the heart must fluctuate through a wide range. It is obvious that there is likewise a wide variation in the conditions of blood flow in them.
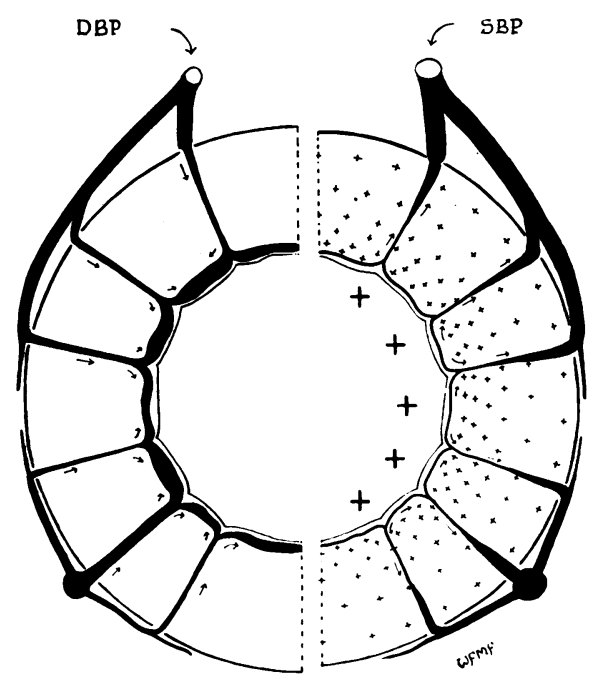

DIASTOLE

EARLY SYSTULE

FIG. 6.-Phasic conditions of blood flow in deep vessels of the left ventricle. For purposes of illustration the dimensions of the "reservoir" formed by the subendocardial vessels have been exaggerated. During systole there is a gradient of pressure indicated by small crosses, which causes severe compression of the more deeply placed arteries and retrograde blood flow towards the superficial vessels.
During diastole, the intramural pressure is low and we may suppose that the deep myocardial arteries are charged with blood, under the influence of the diastolic pressure in the main coronary arteries. The commencement of systole presumably finds these deep vessels turgid with blood. To some extent myocardial contraction may assist in pulsing the blood in its forward course from capillaries to veins; but in the larger vessels composing the subendocardial network, and in other deeply placed arterial branches, the situation may well be different.

When the heart muscle contracts, the turgid subendocardial vessels must inevitably be compressed, either between groups of muscle fibres or between the muscle and the contents of the ventricular cavity. One may suppose that with the onset of systole the blood contained in the subendocardial 'reservoir' will seek such natural exit as may be available. One likely route of escape is towards the arteries on the surface of the heart. This will, of course, involve reversal of flow. I have confirmed that anatomical channels through which the subendocardial reservoir may readily empty itself in this fashion do in fact exist (Fulton, 1961a), the arteries linking the epicardial and deep vessels taking a direct 
route and showing little diminution in calibre. Their capacity to perform this function however could be annulled by two theoretical circumstances that require examination: (1) contraction of the myocardium in such a fashion that the more superficial portions of the myocardial arteries were compressed earlier and with greater force than the deeper portions, so opposing outward flow during systole and (2) a higher pressure of blood in the superficial arteries than in the deep vessels could resist or reverse the tendency to outward flow.

In regard to the first of these, the evidence of electrocardiography indicates that the wave of contraction travels from the deeper layers of the ventricles to the surface. Accordingly, those portions of a myocardial vessel that are deeply situated will be compressed before its more superficially placed portions. Admittedly the time interval is very brief but it is not necessarily negligible.

More important, however, is the convincing work of Johnson and Di Palma (1939) who demonstrated a gradient of pressure within the myocardium of the left ventricle of the cat. They found that the inner layers of the left ventricle developed a pressure at the height of systole, which was in excess of the aortic pressure and therefore of the coronary systolic pressure; whereas the pressure in the superficial layers was much lower and was usually less than the aortic pressure. These findings are fully compatible with established views on cardiac dynamics: both in its direction and its pressure gradient, a wave of compression favours coronary blood flow from the deeper layers towards the surface of the heart.

The arrival from the aorta of the systolic pulse wave in the coronary arteries is the only available force that can resist this outward flow from the deeper vessels. There will, of course, be a short interval of time during and immediately after the isometric phase of ventricular contraction when the outward flow of blood will be opposed. This interval ends with the arrival of the systolic pulse. Nevertheless, since the pressure at the height of systole is higher in the deeper layers of the myocardium than in the coronary arteries, it is likely that outward flow from the subendocardial 'reservoir' continues until it is emptied of blood. On the other hand, experimental evidence suggests that blood enters the vessels of the superficial layers of the left ventricle during the course of ventricular systole. Accordingly it may be supposed that outward flow may be halted or reversed at this level. With the onset of diastole the deep vessels again fill and become turgid, ready for compression to reverse the flow during the next systolic contraction.

Now, in the presence of obstruction to a coronary artery, the arrival of the systolic pulse in the epicardial vessels distal to the obstruction will be delayed for a longer time than in regions with a healthy arterial supply; and the pressure will be lower. These circumstances are probably of paramount importance in the production of the anastomotic patterns seen in the depths of the myocardium in coronary artery disease. For such conditions will favour a larger and more complete emptying flow from the subendocardial plexus in the region of ischæmia than at other parts. Moreover, since the subendocardial vessels are intercommunicating, blood from all parts of the 'reservoir' may seek exit into the relatively low pressure area distal to the arterial occlusion. If this is in fact the case, the relatively extensive nature of the changes found in the deeper vessels in the presence of localized ischæmia is explained.

The situation in generalized myocardial ischæmia with universal involvement of the deep plexus has probably essentially similar origins. Initially it is likely that differential pressure gradients exist between different sectors of the deep plexus and promote its enlargement. By the time severe obliterative disease has overtaken most of the major coronary branches on the surface of the heart, the pressure gradients in the deep vessels may well have undergone several changes of direction. Evidence has been presented that myocardial ischæmia in these cases was evenly distributed in the deeper layers of the left ventricle (Fulton, 1956). This does not mean that the conditions of blood flow in the deep plexus were likewise equitable. On the contrary, an even distribution of blood throughout the deep network, which may be fed mainly at one or two points, would call for intrinsic conditions of blood flow far from sluggish.

Moreover, it is likely that the differential pressure between the left ventricular cavity and epicardial coronary arteries distal to occlusions, where most or all major vessels have been compromised 


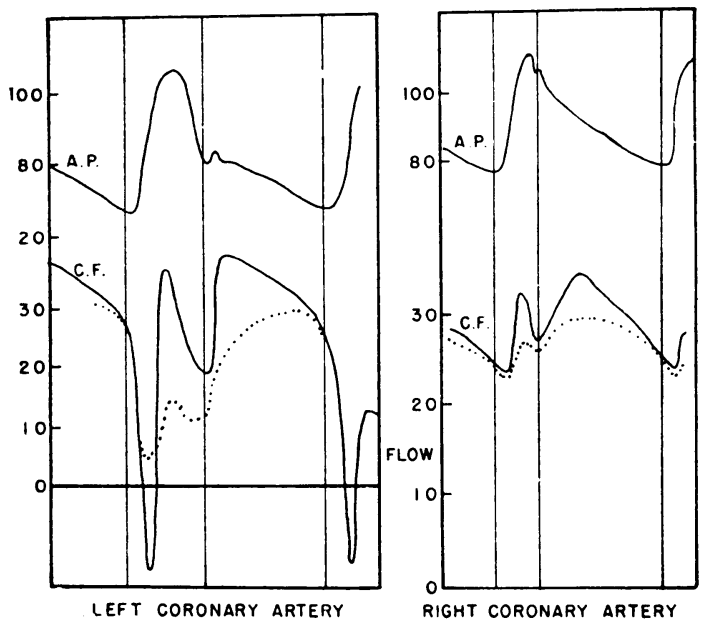

FIG. 7.-(From Gregg, 1950). Reconstruction and comparison of typical flow curves obtained with the orifice meter from the anterior descending branch of the left coronary artery in a small dog and from the right coronary artery in a large dog. A.P. is aortic pressure; C.F. coronary inflow. Ordinates: upper, $\mathrm{mm}$. $\mathrm{Hg}$; lower, flow in $\mathrm{ml} . / \mathrm{min}$ Vertical intercepts demarcate systole and diastole. Dotted lines, predicted intramural velocity curves. by disease, is greater than in the normal state; and that this differential pressure will favour augmentation of ebb-and-flow conditions in the deep plexus.

The foregoing description has envisaged ebband-flow of blood, with each cardiac cycle, in the subendocardial and other deeply situated myocardial arteries. The phenomenon of enlargement of anastomoses is most readily interpreted in terms of a dynamic stimulus to enlargement resident in increased blood flow through the vessels concerned. Conversely, it has been postulated that enlargement of these structures may permit the inference that they were accustomed to carry increased volumes of blood during life. To judge from the changes in the deep vessels of the coronary circulation, this stimulus would seem likewise to be effective when the direction of flow is reversed.

In the normal heart the ebb-and-flow of blood is doutless small in volume. Yet it may be noted, none the less, that the calibre of the vessels composing the normal subendocardial plexus is rather larger than that of the myocardial vessels that supply it. It is tempting to correlate the slight increase in lumen diameter of these vessels with increased movement of blood within them. In the abnormal heart the position is on more secure ground, because of the gross nature of the changes. When the deep plexus of the left ventricle is seen in a greatly dilated state, it is easier to accept that increased movement of blood should determine the enlargement of the vessels that compose it.

The greater the ebb-flow, the greater is the stimulus to further vascular enlargement. Conversely, the greater the vascular dilatation, the greater will be the volume of the subendocardial 'reservoir', and in turn the greater the volume of ebb-and-flow possible. In this way a cycle may be set up. As the movement of the blood is of to-and-fro character, the occurrence of increased movement of blood is compatible with diminished effective flow. In this concept may lie the explanation of the paradox of dilated arteries in an area of ischæmia.

\section{CORRELATION WITH EXPERIMENTAL EVIDENCE}

The interpretation of phasic coronary arterial flow within the myocardium that I have outlined could be, and was in fact, reached through seeking correlation between structure and function, when contemplating the significance of the detailed changes in the deep vessels of the heart.

The conditions of phasic blood flow in these deep vessels may also be inferred from experimental observations on blood flow in the major coronary arteries on the surface of the beating heart. My own deductions are in accord with the experimental findings of a number of workers, whose observations on coronary blood flow are summarized by Wiggers (1949), Blumgart et al. (1950), and by Gregg (1950) (Chapter 5). In Gregg's Fig. 39 (Fig. 7) may be seen illustration of the abrupt reduction in, and finally reversal of, left coronary flow rate during and shortly after the isometric phase of ventricular contraction. The close relation which this curve bears to cardiac contraction is entirely in keeping with regurgitant flow from the myocardial into the epicardial vessels. By the same token, it is unlikely that back flow in the coronary arteries is simply a rebound phenomenon. 
Further, it is highly significant that the curves obtained of right coronary phasic flow are of much smaller amplitude and do not show reversal of flow (Gregg, 1950). This is in keeping with the much lower intramural pressure obtaining in the right ventricle during systole than in the right coronary artery at any phase of the cardiac cycle. Observations on coronary arterial pressure tracings distal to experimentally-created occlusion (Wiggers, 1950) are also in keeping with this concept.

From the available experimental evidence Gregg (1950) writes "During isometric contraction and early injection, the blood in the deeper lying and more strongly compressed coronary vessels is forced backward into the larger proximal channels and, by thus contributing to the supply of blood available for the less strongly compressed and more superficial vessels, reduces the inflow from the aorta." My own observations add little to this concept of normal conditions of coronary blood flow-which also depends on inference-save confirmation from a structural standpoint. I have, however, tried to correlate pathological changes of calibre in the deep vessels with abnormal conditions of blood flow in the walls of the left ventricle; and to find an explanation in terms of causal relationship between altered function and structure. These observations have also provided a better understanding of the conditions of deep blood flow likely to exist in the normal heart.

\section{SUMMARY}

A series of 59 human hearts was examined by a method based on stereo-arteriography: 25 had advanced coronary artery disease.

The arteriographic evidence indicated that the common factor in the promotion of anastomotic enlargement was the presence of conditions favouring differential blood flow between branches of the coronary arteries. Observations are illustrated with examples. It was also evident that the hæmodynamic stimulus to enlargement of anastomoses was operative, not only in areas rendered ischæmic by coronary artery obstruction but also in those well-provided neighbouring arterial territories through which the collateral blood flow had coursed. The apparently paradoxical dilatation of the deep anastomoses of the left ventricle in conditions of severe and widespread obstruction to the entry of blood into the coronary circulation is explained in terms of increased ebb-and-flow movement of blood in these vessels.

The conditions governing phasic blood flow in the depths of the left ventricle are discussed. The concepts derived from animal experiments are correlated with the structural findings of arteriography. In turn, inference on conditions of blood flow in the deeper layers of the heart muscle are advanced on a basis of adaptive changes in the channels that had carried that flow in life. Conditions of blood flow are considered under normal circumstances and in the presence of coronary artery obstruction.

The investigation was begun in the course of a research appointment in the University of Edinburgh, created on the initiative of Dr. A. Rae Gilchrist and sponsored by the Department of Health for Scotland. The original work was carried out in the Departments of Pathology in the University of Edinburgh under Professor A. Murray Drennan and in the Royal Infirmary, Edinburgh, under Dr. R. F. Ogilvie, and in the Department of Anatomy under the late Professor J. C. Brash. The study was continued during the tenure of a lectureship in the Department of Materia Medica and Therapeutics in the University of Glasgow. To those mentioned, and to many others, grateful acknowledgment is made for facilities afforded and for advice and criticism. The clinical records were carefully documented by members of the Department of Cardiology, the Royal Infirmary, Edinburgh, under Dr. Gilchrist. I am indebted to Mr. P. S. Waldie, Department of Clinical Photography, Stobhill General Hospital, Glasgow, for photographic reproduction of the line drawing and arteriograms. Fig. 7 is reproduced by kind permission of Henry Kimpton, the publishers of Coronary Circulation in Health and Disease, by Gregg.

\section{REFERENCES}

Anitschkow, N. (1960). Zur Morphodynamik der Koronarskerose des Herzens. Acta path. microbiol. scand., $49,426$.

Blumgart, H. L., Zoll, P. M., Freedberg, A. S., and Gilligan, D. R. (1950). The experimental production of intercoronary arterial anastomoses and their functional significance. Circulation, 1, 10.

Eckenhoff, J. E., Hafkenschiel, J. H., Landmesser, C. M., and Harmel, M. (1947). Cardiac oxygen metabolism and control of the coronary circulation. Amer.J. Physiol., 149, 634. 
Eckstein, R. W. (1955). Development of interarterial coronary anastomoses by chronic anemia. Disappearance following correction of anemia. Circulat. Res., 3, 306.

Fulton, W. F. M. (1956). Chronic generalized myocardial ischæmia with advanced coronary artery disease. Brit. Heart J., 18, 341 .

- (1960). Observations on the coronary arteries. A study of the anatomy of the circulation of the human heart in health and disease, aided by stereoarteriography, together with observations on the microanatomy of coronary atherosclerosis and thrombosis, and notes on the pathogenesis of these conditions. M. D. Thesis, Glasgow.

- (1963a). Arterial anastomoses in the coronary circulation. I. Anatomical features in normal and diseased hearts demonstrated by stereoarteriography. Scot. med.J., 8, 420.

- (1963b). Arterial anastomoses in the coronary circulation. II. Distribution, enumeration and measurement of coronary arterial anastomoses in health and disease. Scot. med.J. In the press.

- (1963c). Immersion radiography of injected specimens. Brit.J. Radiol., 36, 685.

- (1964a). The time factor in the enlargement of anastomoses in coronary artery disease. Scot. med.J. In the press.

(1964b). Anastomotic enlargement and ischæmic myocardial damage. Brit. Heart J., 26, 1

Green, H. D., and Wégria, R. (1942). Effects of asphyxia, anoxia and myocardial ischemia on the coronary blood flow. Amer. J. Physiol., 135, 271.

Gregg, D. E. (1950). Coronary Circulation in Health and Disease. Lea and Febiger, Philadelphia.

- , and Green, H. D. (1940). Effects of viscosity, ischemia, cardiac output and aortic pressure on coronary blood flow measured under a constant perfusion pressure. Amer. J. Physiol., 130, 108.

Gross, L. (1921). The Blood Supply to the Heart. Hoeber, New York.

Holman, E. (1949). Problems in the dynamics of blood flow: I. Conditions controlling collateral circuletion in the presence of an arteriovenous fistula, following the ligation of an artery. Surgery, 26, 889.

Hughes, A. F. W. (1935). Studies on the area vasculosa of the embryo chick: I. The first differentiation of the vitelline artery. J. Anat. (Lond.), 70, 76.

- (1937). Studies on the area vasculosa of the embryo chick: II. The influence of the circulation on the diameter of the vessels. J. Anat. (Lond.), $72,1$.

Johnson, J. R., and Di Palma, J. R. (1939). Intramyocardial pressure and its relation to aortic blood pressure. Amer. J. Physiol., 125, 234.

Longland, C. J. (1953). The collateral circulation of the limb. Ann. roy. Coll. Surg. Engl., 13, 161.

Mautz, F. R., and Beck, C. S. (1937). The augmentation of collateral coronary circulation by operation. J. thorac. Surg., $7,113$.

Nothnagel, H. (1889). Ueber Anpassungen und Ausgleichungen bei pathologischen Zuständen. Z. klin. Med., 15, 42 .

Sewell, W. H. (1961). Physiologic and technical requirements for experimental strong stimulation of coronary collateral arteries. Circulation, 24, 1036.

Spalteholz, W. (1907). Die Coronararterien des Herzens. Verh. anat. Ges., 21, 141. (In Anat. Anz., 30 Ergänzungsheft.)

Wi (1924). Die Arterien der Herzwand. Anatomische Untersuchungen an Menschen und Tierherzen. Hirzel, Leipzig.

Wiggers, C. J. (1949). Physiology in Health and Disease, 5th ed. Kimpton, London. (1950). The problem of functional coronary collaterals. Exp. Med. Surg., 8, 402.

Zoll, P. M., Wessler, S., and Blumgart, H. L. (1951a). Angina pectoris: a clinical and pathologic correlation. Amer. J. Med., 11, 331 .

,$--\frac{1}{-}$, and Schlesinger, M. J. (1951b). Interarterial coronary anastomoses in the human heart, with particular reference to anemia and relative cardiac anoxia. Circulation, 4, 797. 